\title{
Aproximação ao debate recente sobre a articulação teoria e prática na formação docente em teses e dissertações em educação
}

\section{Approach to the recent debate on articulation theory and practice in teacher education in theses and dissertations in education}

\author{
Sandy Lima Costa ${ }^{1}$ \\ Diana Aguiar Salomão ${ }^{2}$ \\ Isabel Maria Sabino de Farias ${ }^{3}$
}

\section{Resumo}

O presente artigo apresenta uma discussão sobre o binômio teoria e prática na formação de professores a partir da produção acadêmica nacional vinculada a programas de pós-graduação stricto sensu em Educação. O questionamento propulsor dessa pesquisa é: como o tema acerca da articulação entre teoria e prática se faz presente na produção acadêmica nacional decorrente dos programas de pós-graduação em Educação? Objetivamos examinar a abordagem dispensada ao tema da articulação entre teoria e prática na produção acadêmica nacional vinculada aos programas de pós-graduação em Educação (teses e dissertações). Para o alcance do objetivo proposto, foi realizado um levantamento bibliográfico, com abordagem qualitativa, de teses e dissertações, utilizando os descritores "articulação teoria e prática" e "curso de Pedagogia". Foram identificadas 8 produções, 4 dissertações e 4 teses, considerando o período 2006 a 2016. O aporte teórico apoiou-se nas formulações de Cruz (2012), Garcia (1999), Ghedin, Oliveira e Almeida (2015), Giovanni e Guarnieri (2014), Nóvoa (2009), Pimenta e Lima (2004), Saviani (2007), Vaillant e Marcelo (2012), Vázquez (2007), dentre outras. A análise das produções evidenciou que, embora com foco temático distinto, todas as oito produções buscam a compreensão do processo formativo docente, no entanto a discussão sobre essa articulação na formação docente não foi central nos estudos localizados. Com base nessa constatação, ressaltamos a necessidade de aprofundamento das discussões sobre a articulação teoria e prática na formação dos professores como temática central de estudos acadêmicos de teses e dissertações.

Palavras-chave: Articulação teoria e prática; Teses e dissertações; Formação de professores.

\begin{abstract}
This paper presents a discussion about the binomial theory and practice in teacher education from the national academic production linked to stricto sensu postgraduate programs in Education. The propelling question of this research is: how the theme about the articulation

\footnotetext{
${ }^{1}$ Mestranda em Educação pela Universidade Estadual do Ceará - UECE; Bolsista da Coordenação de Aperfeiçoamento de Pessoal de Nível Superior - CAPES; email: sandy.lima @ aluno.uece.br

${ }^{2}$ Mestranda em Educação pela Universidade Estadual do Ceará -UECE/PPGE; Professora da Educação Básica da Rede Municipal de Fortaleza; email: aguiar.salomao@aluno.uece.br

3 Doutora em Educação (UFC); Docente da Universidade Estadual do Ceará (UECE); e-mail: isabelinhasabino@yahoo.com.br
}

Revista Devir Educação, Lavras, vol.3, n.2, p.5-26 jul./dez., 2019. 


\section{Q DEVIR EDUCAÇÃO \\ ISSN: 2526-849X}

between theory and practice is present in the national academic production resulting from the postgraduate programs in Education? We aim to examine the approach given to the theme of articulation between theory and practice in national academic production linked to postgraduate programs in Education (theses and dissertations). To achieve the proposed objective, a qualitative bibliographic survey of theses and dissertations was performed, using the descriptors "articulation theory and practice" and "Pedagogy course". Eight productions, four dissertations and four theses were identified, considering the period from 2006 to 2016 . The theoretical support was based on the formulations of Cruz (2012), Garcia (1999), Ghedin, Oliveira and Almeida (2015), Giovanni and Guarnieri ( 2014), Nóvoa (2009), Pimenta and Lima (2004), Saviani (2007), Vaillant and Marcelo (2012), Vázquez (2007), among others. The analysis of the productions showed that, although with a different thematic focus, all eight productions seek the understanding of the teaching formative process, however the discussion about this articulation in the teaching formation was not central in the localized studies. Based on this finding, we emphasize the need for further discussions on the articulation theory and practice in teacher education as the central theme of academic studies of theses and dissertations.

Keywords: Articulation theory and practice; Theses and dissertations; Teacher training.

\section{Introdução}

Este estudo apresenta discussão sobre o binômio teoria e prática na formação de professores a partir da produção acadêmica nacional vinculada a programas de pós-graduação stricto sensu em Educação (teses e dissertações). A análise parte da premissa de que a articulação entre teoria e prática é um desafio histórico nesse campo, especialmente para o professor iniciante, consubstanciando-se no aspecto que mais tenciona os primeiros anos de docência (GARCIA, 1999; NONO, 2011; GIOVANNI; GUARNIERI, 2014).

A formação de professores no Brasil é uma temática contemplada por constantes análises na literatura acadêmica, nas quais a articulação entre teoria e prática revela-se como um aspecto recorrente, configurando-se como uma preocupação que permanece no debate público ao longo da historiografia educacional. Embora seja um assunto presente na formação de professores desde os primórdios da constituição da profissão docente, continua sendo uma problemática atual nos processos de aprender a ensinar, em suas várias etapas (CRUZ, 2012; ANDRÉ, 2012; SAVIANI, 2007).

A problematização em torno da formação tem buscado definir um modelo (concepção) ideal para atender às necessidades dos professores em seus diversificados contextos de atuação profissional, em especial dos professores em início de carreira, que vivenciam 


\section{Q DEVIR EDUCAÇÃO \\ ISSN: 2526-849X}

diferentes dilemas e tensões, como a insegurança e o "choque de realidade", ao se sentirem despreparados por não conseguirem encontrar nas teorias aprendidas na formação inicial, elementos que os auxiliem no desenvolvimento de suas atividades profissionais práticas ao ingressarem na carreira (VEENMAN, 1984 apud GARCIA, 1993).

Para Vaillant e Marcelo (2012) a separação entre teoria e prática é um fenômeno relacionado às ideias prevalecentes sobre o ato de aprender a ensinar nos modelos de formação, ou seja, a compreensão sobre como se aprende, como se ensina e como se aprende a ensinar. Nesse sentido, ao retomarem o argumento de Feiman-Nemser (2001), de que existe uma separação entre "a formação inicial e a realidade escolar", realçam que, historicamente, esta relação tem sido marcada "mais pelo desencontro e pela ignorância recíproca do que por uma colaboração com benefício mútuo" (Ibidem, p.87). O não reconhecimento dessa relação de interdependência encontra-se, para os dois autores, no âmago da desarticulação entre teoria e prática na formação dos professores. Paradoxalmente, arrematam os dois autores supracitados, tanto as instituições de formação quanto a escola se necessitam: aquela precisa dos contextos de práticas para assegurar uma socialização profissional significativa da aprendizagem da docência, enquanto esta precisa da formação inicial para fortalecer conceitual e compreensivamente o fazer docente.

Este entendimento, contudo, não tem orientado as concepções acerca do processo de aprender a ensinar, de modo que ainda hoje o modelo de relação que prevalece entre as universidades e as escolas é o de "justaposição" na formação inicial de professores. Este modelo, conforme Vaillant e Marcelo (2012), não tem favorecido uma relação profícua entre as instituições de formação e a escola, dois importantes contextos da socialização profissional docente. Nele, primeiro é abordado a teoria, o que ocorre ao longo da maior parte da licenciatura, contemplando a prática apenas ao fim da formação, por meio de estágios, configurados como momento de aplicabilidade das teorias e conhecimentos apreendidos (PIMENTA; LIMA, 2004; LIMA, 2004; GHEDIN; OLIVEIRA; ALMEIDA, 2015). É considerado como tradicional, marcado por uma aprendizagem passiva por parte do aprendiz, baseando o aprender a ensinar na prática da imitação.

Contrapondo-se a esta tendência, Denise Vaillant e Carlos Marcelo ponderam sobre os demais modelos de relação entre as instituições formativas e as escolas, por eles identificados como modelo de consonância, de dissonância crítica e o de ressonância colaborativa. Tais modelos podem ser percebidos como caminhos possíveis para pensar a formação inicial e sua 


\section{Q DEVIR EDUCAÇÃO \\ ISSN: 2526-849X}

interligação com o contexto escolar, pois favorecem a articulação teoria e prática através da colaboração entre a universidade e a escola. Eles procuram promover um intercâmbio mútuo entre essas duas instâncias formativas, valorizando a formação centrada na escola para a promoção da aprendizagem da docência.

No modelo de consonância, entende-se que a formação deve promover a aquisição de competências ao aspirante a professor para que esse possa realizar de maneira eficaz a tarefa de ensinar. Através de supervisões ou mentorias busca-se desenvolver uma formação congruente entre o que é ensinado nas instituições de formação e nas escolas. O professor da escola configura-se, neste contexto, como um agente formador que contribui na formação dos futuros professores através de práticas de acompanhamento, recebendo formação para desempenhar tal tarefa.

Já o modelo de dissonância crítica, preocupa-se em desenvolver nos docentes em formação uma atitude crítica, reflexiva e investigativa em relação às práticas de ensino, não limitando o ensino a mera aquisição de competências. Aprender a ensinar, segundo este modelo, é um processo de experiências práticas e reflexões sobre essas experiências.

No que concerne ao modelo de ressonância colaborativa, este busca desenvolver uma relação de colaboração com benefício mútuo entre universidades e escolas. Ambas são basilares no processo de aprender a ensinar e fomentam reflexões e conhecimentos assegurados na partilha, reafirmando assim, a importância da parceria entre universidade e escola.

Considerando os quatro modelos de relação entre universidades e escolas apresentados por Vaillant e Marcelo (2012), podemos dizer que o de justaposição é o único que não oferece a oportunidade de aprender a docência no futuro ambiente de trabalho, a escola, em colaboração com professores mais experientes ao longo da formação inicial.

As análises de Vaillant e Marcelo (2012) evidenciam o modelo de justaposição como restritivo da articulação teoria e prática por desconhecer a natureza complexa do ato educativo e as suas várias dimensões, com isso reforçando a hierarquização entre teoria e prática, acentuando ainda mais o distanciamento entre a universidade e a escola (CRUZ, 2012; SAVIANI, 2007).

De acordo com a Lei de Diretrizes e Bases da Educação - LDB/1996, em seu Art. 61, inciso I, a formação dos profissionais da educação deve contemplar a associação entre teorias e práticas, considerando os diferentes níveis e modalidades de ensino e as características de 


\section{Q DEVIR EDUCAÇÃO \\ ISSN: 2526-849X}

cada fase do desenvolvimento do educando. No entanto, resultados de pesquisas recentes têm destacado "que professores recém-formados [...] rendem-se facilmente à cultura da escola, na maioria das vezes abandonando os referenciais da ciência que os formou", anotam Ghedin, Oliveira e Almeida (2015, p. 36). Também é nessa direção que Marli André nos alerta para a necessidade de discussão da atuação da universidade na formação de futuros professores ao destacar que pesquisas sobre a formação de professores apontam que:

As novas exigências colocadas ao trabalho dos professores na sociedade contemporânea e o reconhecimento de que a formação nos cursos de licenciatura não vem oferecendo aos licenciandos os conhecimentos e habilidades necessárias para enfrentar os desafios da docência colocam em discussão a atuação da universidade na formação dos docentes (ANDRÉ, 2012, p. 102).

A literatura acerca da articulação entre os componentes teoria e prática, no campo da formação, revela que ela se constitui um problema complexo e amplamente debatido no cenário educacional, o que, em tese, faz parecer que já está sendo solucionado, mas que na verdade permanece como um desafio posto à Educação, pois ainda temos dificuldades de construir e efetivar modelos de formação que assumam uma posição simétrica entre teoria e prática. Uma questão que registra denso debate, mas, como anota Nóvoa (2009), ainda apresenta práticas pobres e tímidas em seu enfrentamento nos processos de aprender a ensinar.

Ao reconhecer a relevância da articulação entre teoria e prática para o debate sobre a formação de professores, em particular para aqueles que vivenciam os primeiros anos da carreira, o presente trabalho assumiu como objetivo analisar e apresentar a abordagem dispensada a esse tema na produção acadêmica nacional vinculada aos programas de pósgraduação em Educação (teses e dissertações). Desse modo, foi movido pelo seguinte questionamento: Como o tema da articulação entre teoria e prática na formação de professores pedagogos se faz presente na produção acadêmica nacional decorrente dos programas de pósgraduação em Educação? Dessa preocupação inicial decorrem as demais indagações norteadoras desta análise: Quais os temas mais abordados nas teses e dissertações referentes a articulação teoria e prática na formação de professores? Qual o foco do problema de pesquisa 


\section{Q DEVIR EDUCAÇÃO \\ ISSN: 2526-849X}

dessas produções? Qual o aporte teórico utilizado? Quais as metodologias? Quem são os sujeitos? Há produções que focalizam o professor iniciante?

Para alcançar o objetivo proposto e responder estas inquietudes, foi realizado um levantamento bibliográfico com abordagem qualitativa, no período de 15 a 24 de julho de 2019, na Biblioteca Digital Brasileira de Teses e Dissertações (http://bdtd.ibict.br/vufind/), a qual reúne as teses e dissertações do país, possibilitando o acesso e a busca a esses documentos em um só portal.

Para a identificação das fontes foram utilizados os seguintes descritores: "Articulação teoria e prática" e "Curso de Pedagogia". Na busca com esses descritores usamos aspas nos termos com o fito de encontrarmos registros que contenham as palavras juntas, bem como selecionamos resumo em português como critério de filtramento. Localizamos oito produções, sendo quatro teses e quatro dissertações, defendidas entre os anos de 2006 a 2016. Empreendemos uma análise de conteúdo (BARDIN, 2004) das produções encontradas, realizando um exame dos títulos, resumos e palavras-chave.

O aporte teórico deste estudo apoiou-se nas formulações de Cruz (2012), Garcia (1999), Ghedin, Oliveira e Almeida (2015), Giovanni e Guarnieri (2014), Lima (2004), Nono, (2011), Nóvoa (2009), Pimenta e Lima (2004), Saviani (2007), Vaillant e Marcelo (2012) e Vázquez (2007). No tópico seguinte, trazemos uma breve discussão sobre teoria, prática e a articulação destes componentes na formação de professores.

\section{Notas sobre o binômio teoria e prática na formação docente}

A formação de professores como processo do aprender a ensinar é perpassada por fases que constituem a identidade docente, as quais são marcadas por momentos de desequilíbrio, aprendizagens, desaprendizagens e mudanças de concepções e práticas educativas (IMBERNÓN, 2010; GARCIA, 1999). Trata-se de um aprendizado profissional ao longo da vida e que requer o envolvimento dos professores em processos intencionais e planejados que articulem o eu pessoal, o eu profissional e o eu nas condições sócio-históricas do trabalho, assinalam autores como Pimenta (1999), Nóvoa (1995, 2000), Imbernón (2010) e Garcia (1999). Nesses termos, ela precisa ser pensada integrando a pluralidade de saberes da profissão e essas diversas dimensões, de modo a possibilitar aos sujeitos em formação subsídios (teóricos e práticos) que os qualifiquem para realizar intervenções profissionais que favoreçam o desenvolvimento do ensino, do currículo e da escola. 


\section{Q DEVIR EDUCAÇÃO \\ ISSN: 2526-849X}

Para Formosinho (2009), a docência é uma profissão que se aprende desde que se entra na escola, pela vivência da discência e pela observação do comportamento dos nossos professores. Em sendo assim, a formação do professor não se inicia com o curso profissional, mas decorre de toda a sua experiência como aluno na Educação Básica e no curso de licenciatura, compreensão que leva o autor português a propor que as práticas pedagógicas dos docentes formadores devem ser assumidas como componente curricular da formação prática dos futuros professores.

Com isso, podemos dizer que a profissionalidade e a identidade docente têm sua gênese antes mesmo da formação inicial, pois o futuro professor constitui suas primeiras aprendizagens sobre a profissão docente ainda na fase da pré-formação, e tais aprendizagens influenciam o seu itinerário formativo tanto durante a formação inicial quanto no período de iniciação e de formação continuada (GARCIA, 1999). Compreendemos que todas essas fases constituem o desenvolvimento profissional docente, porém neste escrito queremos chamar atenção para a formação inicial.

A formação inicial é concebida como o primeiro momento de socialização e aprendizagem formal da profissão, e desde a promulgação da LDB $\mathrm{n}^{\circ}$ 9.394/96, especificamente em seu capítulo VI, que trata dos profissionais da educação, é prevista para acontecer em instituições superiores de ensino e formação de futuros professores por meio de sólida fundamentação teórica, articulada com a prática e interligada com a escola. Esta orientação corrobora a formulação de Garcia (1999) quando afirma que as instituições formativas de profissionais para a docência possuem três finalidades, a saber: formação e aprendizagem das funções que o professor irá desempenhar; permissão para o exercício da profissão docente; e, a dupla função de agente da mudança e socializador e reprodutor da cultura vigente.

Diante deste entendimento, a formação inicial docente deveria ser o espaço-tempo em que o aspirante a professor adquire bagagem teórica e prática para a articulação dos conhecimentos essenciais para atuar como docente, além de se preparar para a diversidade existente no ambiente escolar, dirimindo um possível "choque de realidade" no futuro, levando-o à compreensão desta realidade de maneira contextualizada e a promoção da reflexividade e da criticidade pedagógica. É consenso entre pesquisadores da educação (CRUZ, 2012; GARCIA, 1999, GATTI, 2014), entretanto, que os modelos de formação 


\section{Q DEVIR EDUCAÇÃO \\ ISSN: 2526-849X}

instituídos não têm fornecido a base necessária para o aprendizado dos saberes, uma vez que tendem a priorizar o campo teórico em detrimento da prática.

Explicitar o significado dos vocábulos teoria e prática nos parece fundamental à compreensão das implicações que sua separação traz para a formação dos professores. Etimologicamente, estes dois termos derivam do grego: teoria advém de théorin, que significa observar, contemplar, refletir (GARCIA, 1977); prática deriva de práxis, praxeos, possuindo o sentido de agir, de ação inter-humana consciente (CANDAU; LELIS, 1999).

É com o filósofo grego Platão que o termo teoria passa a ser associado ao ato especulativo de atividades eminentemente práticas e, hodiernamente, refere-se a qualquer "ordenamento sistemático de ideias acerca dos fenômenos de um determinado setor de investigação" (GARCIA, 1977, p.119). É também recorrente na sua tematização, alerta Vázquez (1977), a tendência a contrapô-lo a noção de prática, caracterizando-os como duas realidades excludentes entre si ou, pelo menos, como tese e antítese de um mesmo processo. A esta perspectiva, este autor espanhol formula o argumento de que a teoria "só existe por e em relação com a prática" (Ibidem, p, 202), reforçando a premissa de que apenas “artificialmente, por processo de abstração", é possível separar teoria e prática.

É entre posições que dicotomizam e que postulam a unidade que o debate acerca dos termos teoria e prática na formação de professores se constitui (CANDAU, 1998). A primeira atribui total autonomia de um termo em relação ao outro, seja como componentes isolados, opostos ou mesmo justapostos; a segunda se caracteriza pela união da teoria e prática sem perda da respectiva identidade, movimento que os compreende como componentes indissolúveis da práxis. Na base dessas posições, o que está em questão é a compreensão sobre como se aprende, como se ensina e como se aprende a ensinar, conforme assinalamos anteriormente.

Esta breve digressão em torno dos termos teoria e prática nos permite compreender as ponderações de Garcia (1999) ao aludir ao modelo formativo de justaposição como difusor e fortalecedor de uma formação de professores baseada na observação e na imitação do "que os bons professores fazem". Com efeito, no contexto brasileiro, a formação inicial de professores foi constituída e se desenvolveu ao longo da história educacional brasileira baseada no modelo formal de escolarização e com forte influência do tradicionalismo e da academização, fornecendo referências insuficientes e parciais sobre o ensino e a complexidade dos desafios que os professores em início de carreira se deparam. Não é a toa que a literatura sobre o 


\section{OO DEVIR EDUCAÇÃO \\ ISSN: 2526-849X}

assunto destaca que a formação inicial docente tem sido marcada pelo desencontro entre a teoria trabalhada nas Instituições de formação e as experiências práticas oportunizadas através do contato com a escola, sendo considerado um embate histórico, principalmente no curso de Pedagogia (CRUZ, 2012; VAILLANT; MARCELO, 2012).

Uma expressão desse embate encontra-se nas críticas que cercam o currículo de formação dos professores no Brasil, incorrendo em buscas por soluções quanto a sua configuração. O levantamento sobre os currículos dos cursos de licenciatura em Pedagogia, realizado por Gatti (2010), é emblemático desse movimento em âmbito mais recente. Esta autora constatou que dos 71 currículos analisados, contemplando instituições de todo o país, as 3.513 disciplinas investigadas privilegiam, em sua maioria, os conteúdos teóricos em detrimento da prática no ambiente escolar, e dentre estes conteúdos verifica-se a presença, sobretudo, de disciplinas sociológicas, políticas, filosóficas, históricas e psicológicas. Ou seja, estuda-se bastante sobre teorias educacionais, porém, pouco é tratado sobre a realidade palpável da escola e o contexto de atuação docente.

Somente durante os Estágios Supervisionados, reconhecidos como componentes curriculares essencialmente práticos, é que os futuros professores se aproximarão da realidade em que atuarão, obtendo um contato concreto com o ambiente escolar a fim de serem colocadas em prática as teorias aprendidas no decorrer do curso, e refletir, a partir dessas vivências (PIMENTA; LIMA, 2006). Além disso, é no momento dos estágios que são oportunizadas as contribuições para que o jovem licenciando se reconheça como um adulto professor em processo de aprendizagem e firme sua identificação com a docência.

A esse respeito, Pimenta (1997) pondera que estudos realizados têm revelado que os cursos de formação inicial, ao executarem um currículo formal com conteúdos e atividades de estágios distantes da realidade das escolas e, seguindo uma perspectiva burocrática e cartorial, que não contempla as contradições presentes na prática social de educar, têm gerado pouca contribuição para desenvolver a identidade do profissional docente.

O percurso histórico da formação de professores no contexto nacional envolveu diversos embates entre associações e entidades educacionais, movimentos e fóruns da sociedade civil junto ao Conselho Nacional de Educação (CNE) e ao Ministério da Educação (MEC), e um dos resultados desse intenso movimento foi a publicação da Resolução $\mathrm{n}^{\circ} 2$, de $1^{\circ}$ de julho de 2015, que fixa as Diretrizes Curriculares Nacionais para a formação inicial em 


\section{Q DEVIR EDUCAÇÃO \\ ISSN: 2526-849X}

nível superior (cursos de licenciatura, cursos de formação pedagógica para graduados e cursos de segunda licenciatura) e para a formação continuada, sendo um importante marco legal.

Nesse documento, foram definidos princípios e fundamentos para o desenvolvimento da formação inicial docente, sendo proposto que os cursos de licenciatura ofertassem 3.200 (três mil e duzentas) horas em sua carga horária, contemplando 400 (quatrocentas) horas de atividades de cunho prático e 400 (quatrocentas) horas dedicadas ao estágio curricular supervisionado, na área de formação e atuação na Educação Básica (BRASIL, 2015). A respeito da articulação entre teoria e prática, a Resolução CNE/CP n 2/2015, em seu no Art. 13, parágrafo $3^{\circ}$, prevê que na formação inicial de professores para a Educação Básica em nível superior "Deverá ser garantida, ao longo do processo, efetiva e concomitante relação entre teoria e prática, ambas fornecendo elementos básicos para o desenvolvimento dos conhecimentos e habilidades necessários à docência" (BRASIL, 2015, p.11). No entanto, ainda é comum, em especial nos discursos dos licenciandos em Pedagogia, que o curso fornece um preparo docente prioritariamente no campo teórico, distanciando-se de experiências referentes ao cotidiano escolar e ao exercício profissional (CHIARELO, 2017). Acreditamos que o reconhecimento da necessidade da articulação teoria e prática na legislação representa passo importante para sua concretização nas instituições de ensino superior, porém, isso é apenas uma possibilidade, e não uma certeza, pois, historicamente, a experiência nacional revela que a educação é um campo resistente a mudanças (FRANCO, 2012).

De acordo com Fullan (1991), a mudança em educação relaciona-se a um processo social mais amplo que envolve os atores das práticas cotidianas, as condições objetivas e os valores culturais. Diante disso, podemos dizer que a incorporação das concepções vigentes das legislações nas práticas pedagógicas das instituições de ensino, responsáveis pela formação inicial dos professores, depende da cultura vivenciada e construída pelos sujeitos desses espaços educacionais, ou seja, do que eles pensam e fazem, como também das condições subjetivas e objetivas de trabalho, do desenvolvimento profissional e da valorização desses profissionais.

Desse modo, é a cultura institucional e a cultura docente vivenciada em cada instituição que pode ou não possibilitar as mudanças na educação (FARIAS, 2006), pois, como aponta Franco (2012), as mudanças e transformações das práticas educacionais não 


\section{OO DEVIR EDUCAÇÃO \\ ISSN: 2526-849X}

acontecem por leis, diretrizes, decretos, propostas curriculares ou imposições, elas dependem do envolvimento crítico e reflexivo de seus protagonistas.

As análises evidenciam que um dos aspectos que pode garantir a articulação entre teoria e prática, prevista nos documentos oficiais e amplamente discutida na literatura científica brasileira, é a práxis dos sujeitos que compõem os espaços educacionais de formação de professores. Segundo Pimenta (1995, p. 63), “A atividade teórico-prática de ensinar constitui o núcleo do trabalho docente".

É durante a formação inicial que o aprendizado dos saberes considerados como necessários à atuação no magistério é oportunizado: saberes da experiência (vivências adquiridas e trazidas por meio do ambiente universitário); do conhecimento (científicos); e, saberes pedagógicos (momentos práticos) (PIMENTA, 1997). Para tanto, é preciso que os cursos de formação de professor incorporem efetivamente estes saberes em seus currículos, visando garantir uma formação que reconheça de fato a importância dos saberes teóricos e práticos para a atuação no magistério, partindo da compreensão que a atividade docente não é um simples ato de ministrar aulas, mas é práxis. "As dimensões de conhecimento e de intencionalidade (atividade teórica) e a de intervenção e transformação (atividade prática) da atividade docente conferem-lhe o sentido de atividade teórico-prática - ou práxis" (PIMENTA, 1995, p. 61), a qual se constitui como uma atividade específica e necessária em um curso de formação inicial, se o intuito é promover uma formação docente integral e de qualidade.

Dissociar a teoria da prática colabora para que o trabalho do professor não se desenvolva de maneira reflexiva, e assim, não promove a transformação da realidade material e social. Ressaltamos que a teoria e a prática, sozinhas, não conduzem a uma transformação da realidade, tampouco a práxis. Ambos os componentes são constituintes desta atividade específica, de maneira articulada (PIMENTA, 1995).

Desenvolver um curso de formação de professor que articule esses componentes no âmbito da práxis no processo formativo contribuirá, por certo, para um melhor aprendizado da docência, especialmente para o professor iniciante. Esse, recém-egresso da licenciatura, ao ter vivenciado essa articulação durante todo a sua formação inicial, ao chegar na escola de Educação Básica se sentirá melhor preparado para atuar e refletir sobre seu trabalho pedagógico, pois possuirá um embasamento teórico e prático acerca desse contexto de atuação profissional. 
Consideramos que articular, de maneira consciente, o conhecimento teórico com as experiências práticas, assume fundamental importância durante a licenciatura, pois o futuro docente tem a oportunidade de compreender a realidade escolar de maneira contextualizada, para além do que aludem os textos, vivenciando os dilemas e desafios existentes, preparandose melhor para a sua futura atuação docente.

Com arrimo nessa premissa, concordamos com o autor espanhol Marcelo Garcia quando sinaliza a necessidade de uma efetiva revisão no currículo dos cursos de formação de professores, juntamente com o reconhecimento da importância de se promover relações mais estreitas entre as universidades e as escolas, considerando, nessa direção, que a formação inicial de professores se consolidará de maneira completa quando efetivamente realizar a articulação entre teoria e prática.

Este reconhecimento nos levou a indagar sobre o que dizem as teses e dissertações dos programas de pós-graduação em Educação acerca da articulação teoria e prática na formação de professores, especialmente no período de iniciação profissional. No próximo tópico buscamos evidenciar os indicativos oriundos do mapeamento dessas produções.

\section{O que revela a produção científica da pós-graduação stricto sensu em educação sobre a articulação teoria e prática na formação de professores?}

A busca da produção científica recente dos programas de pós-graduação stricto sensu do Brasil, precisamente as teses e dissertações defendidas no período de 2006 a 2016, foi efetivada com o intuito de conhecer o que elas revelam sobre a articulação teoria e prática na formação de professores.

O levantamento dessas produções foi efetuado no mês de julho de 2019, por meio do banco de dados da Biblioteca Digital Brasileira de Teses e Dissertações - BDTD, por compreendermos ser este um portal de busca que abrange textos completos no âmbito dos cursos de mestrado e doutorado em Educação no território nacional. Para tanto, adotamos como descritor primário a categoria central de nossa preocupação: “articulação teoria e prática”. Localizamos 26 trabalhos que contemplam esta categoria em seus resumos em português, no entanto, um era repetido, totalizando assim 25 produções.

Com este primeiro levantamento, foi possível perceber que alguns trabalhos eram pertencentes a programas de pós-graduação em Avaliação de Políticas Públicas, Educação, e Engenharia da produção, além de abordarem cursos como Biologia, Administração, 


\section{Q DEVIR EDUCAÇÃO \\ ISSN: 2526-849X}

Psicologia, História e Tecnologia em Gestão Comercial, distanciando-se do nosso foco - a Pedagogia, a exemplo dos trabalhos de Teixeira (2015) e Viana (2017).

Posteriormente, relacionamos o primeiro descritor com o descritor "Curso de Pedagogia", com o intuito de determos nossas buscas em produções que abordassem especificamente a articulação teoria e prática no curso de Pedagogia, o que resultou na identificação de oito produções com estas duas categorias em seus resumos em português. Desses trabalhos, quatro são dissertações e quatro são teses, defendidas no período de 2006 a 2016.

No que concerne às regiões do país onde foram produzidas as pesquisas localizadas, essas se concentram na região Sudeste, com quatro, seguida da região Nordeste, que possui duas pesquisas. Nas regiões Sul e Centro-Oeste, encontramos uma pesquisa em cada, enquanto na região Norte nenhuma foi localizada. As produções identificadas provêm de três cursos distintos, assim distribuídos: Doutorado em Educação (3), Mestrado em Educação (2), Mestrado em Educação Especial (1), Mestrado em Educação Escolar (1), Doutorado em Educação Escolar (1). O Quadro 1 detalha informações básicas sobre os oito trabalhos encontrados.

Quadro 1: Teses e Dissertações com foco na articulação teoria e prática na formação de professores - 2006 a 2016 (BDTD)

\begin{tabular}{|c|c|c|c|c|c|}
\hline AUTOR & TITULO & CURSO & TIPO & INSTITUIC̣ẢO/ANO & $\begin{array}{l}\text { REGLÄO DO } \\
\text { PAÍS }\end{array}$ \\
\hline $\begin{array}{l}\text { RIBEIRO, } \\
\text { Jacira Chaves }\end{array}$ & $\begin{array}{l}\text { Formação continuada e trabalho } \\
\text { pedagógico: o caso de uma } \\
\text { profegsora egressa do curso de } \\
\text { pedagogia para professores em } \\
\text { exercicio no inicio de } \\
\text { escolarização-PIE }\end{array}$ & $\begin{array}{l}\text { Mestrado em } \\
\text { Educação }\end{array}$ & Dissertação & $\begin{array}{l}\text { Universidade de } \\
\text { Brasilia/2006. }\end{array}$ & $\begin{array}{l}\text { Centro- } \\
\text { Oeste }\end{array}$ \\
\hline $\begin{array}{l}\text { SARTORI, } \\
\text { Jerônimo }\end{array}$ & $\begin{array}{l}\text { Formação do professor em serviço: } \\
\text { da (re)construção teórica e da } \\
\text { ressignificação da prática }\end{array}$ & $\begin{array}{c}\text { Doutorado } \\
\text { em Educação }\end{array}$ & Tese & $\begin{array}{l}\text { Universidade Federal do } \\
\text { Rio Grande do Sul/ } 2009\end{array}$ & Sul \\
\hline $\begin{array}{c}\text { MACEDO, } \\
\text { Natalia Neves }\end{array}$ & $\begin{array}{l}\text { Formação de profegsores para a } \\
\text { educação incluaiva nos cursos de } \\
\text { Pedagogia das Universidades } \\
\text { Públicas Paulistas }\end{array}$ & $\begin{array}{l}\text { Mestrado em } \\
\text { Educação } \\
\text { Especial }\end{array}$ & Dissertação & $\begin{array}{c}\text { Universidade Federal de } \\
\text { São Carlos/2010 }\end{array}$ & Sudeste \\
\hline $\begin{array}{l}\text { MENDES, } \\
\text { Débora Lúcia } \\
\text { Lima Leite. }\end{array}$ & $\begin{array}{l}\text { Estrutura e funcionamento de } \\
\text { ensino e a gestão educacional: } \\
\text { avaliação de disciplinas em cursos } \\
\text { de pedagogia e licenciatura na } \\
\text { Universidade Federal do Ceará }\end{array}$ & $\begin{array}{l}\text { Doutorado } \\
\text { em Educação }\end{array}$ & Tese & $\begin{array}{c}\text { Universidade Federal do } \\
\text { Ceará/2011 }\end{array}$ & Nordeste \\
\hline $\begin{array}{l}\text { FRANCELINO } \\
\text { DE SALES, } \\
\text { Claudemir }\end{array}$ & $\begin{array}{l}\text { O estágio e a politica de formação } \\
\text { do educador: um estudo a partir de } \\
\text { programas e projetos da rede } \\
\text { municipal de ensino do Recife }\end{array}$ & $\begin{array}{l}\text { Mestrado em } \\
\text { Educação }\end{array}$ & Dissertação & $\begin{array}{l}\text { Universidade Federal de } \\
\text { Pernambuco/2011 }\end{array}$ & Nordeste \\
\hline $\begin{array}{c}\text { MELLO, } \\
\text { Marilice } \\
\text { Pereira Ruiz do } \\
\text { Amaral }\end{array}$ & $\begin{array}{l}\text { Formação inicial de professores e } \\
\text { projetos integradores do curso de } \\
\text { Pedagogia: desafios } \\
\text { possibilidades }\end{array}$ & $\begin{array}{l}\text { Doutorado } \\
\text { em Educação }\end{array}$ & Tese & $\begin{array}{c}\text { Pontificia Universidade } \\
\text { Católica de São } \\
\text { Paulo/2013 }\end{array}$ & Sudeste \\
\hline $\begin{array}{c}\text { AMORIM, } \\
\text { Aline Diniz de }\end{array}$ & $\begin{array}{l}\text { O processo de constituição da } \\
\text { identidade docente do professor } \\
\text { iniciante: egressos do curso de } \\
\text { Pedagogia da UNESP/Bauru }\end{array}$ & $\begin{array}{l}\text { Mestrado em } \\
\text { Educação } \\
\text { Escolar }\end{array}$ & Dissertação & $\begin{array}{l}\text { Universidade Estadual } \\
\text { Paulista/2016 }\end{array}$ & Sudeste \\
\hline
\end{tabular}


Fonte: Das autoras (2019).

Todos os trabalhos localizados neste levantamento estavam disponíveis na base consultada (BDTD), no formato PDF. A análise destas produções foi realizada por meio da leitura dos títulos, resumos em português e palavras-chave. A seguir, traremos um exame dos trabalhos identificados.

Como já mencionamos, as oito produções localizadas são resultados de pesquisas finalizadas entre os anos de 2006 a 2016, sendo todas oriundas de instituições públicas e com foco na formação do professor. Na análise dos títulos dessas produções, constatamos que seis trabalhos utilizam a palavra "formação", revelando que a temática da pesquisa contempla o processo formativo docente inicial ou continuado (FRANCELINO DE SALES, 2011; MACEDO, 2010; MELLO, 2013; ; OLIVEIRA, 2016; RIBEIRO, 2006; SARTORI, 2009). Os outros dois trabalhos não apresentam no título o termo "formação", mas fazem uso do termo "curso de pedagogia", dando indícios de que a formação inicial é um tema abordado (AMORIM, 2016; MEDES, 2011).

Ao analisarmos as palavras-chave, identificamos que sete produções trazem a formação docente como categoria de pesquisa. As palavras-chaves que evidenciaram essa identificação foram "formação de professores", "formação inicial” e "política de formação do educador" (AMORIM, 2016; FRANCELINO DE SALES, 2011; MACEDO, 2010; MELLO, 2013; OLIVEIRA, 2016; RIBEIRO, 2006; SARTORI, 2009). Outro aspecto importante a ser destacado sobre a análise das palavras-chave é sobre o uso do termo "articulação teoria e prática”, que foi encontrado apenas no trabalho sobre estágio supervisionado, evidenciando que, em geral, a discussão sobre essa articulação na formação docente não foi central nos estudos localizados (FRANCELINO DE SALES, 2011). 


\section{Q DEVIR EDUCAÇÃO \\ ISSN: 2526-849X}

No que concerne ao tema dessas produções, verificamos que dois trabalhos tratam das relações entre formação inicial e continuada dentro de um contexto de formação em serviço (RIBEIRO, 2006; SARTORI, 2009). Essas duas produções tratam sobre projetos implementados para atender a obrigatoriedade da formação em nível superior para o exercício da docência, sendo assim, abordam a temática da formação inicial em articulação com a formação continuada para professores que exerciam sua carreira docente sem terem uma formação em nível superior.

A respeito dos demais trabalhos, averiguamos que quatro deles abordam o currículo do curso de Pedagogia, A respeito dos demais trabalhos, averiguamos que quatro deles abordam o currículo do curso de Pedagogia, sendo que Macedo (2010) e Oliveira (2016) focalizam a temática da Educação Especial e Inclusiva por meio da análise das contribuições de disciplinas dessa área, o de Mendes (2011) avalia a qualidade do ensino-aprendizagem das disciplinas da área de Estrutura e Funcionamento do Ensino nos cursos de pedagogia e licenciaturas e de Mello (2013) trata sobre os desafios e possibilidades dos projetos integradores de uma instituição enquanto componentes curriculares do Projeto Pedagógico do Curso de Pedagogia para a ressignificação do currículo.

Por fim, em relação aos outros dois trabalhos, aferimos que um aborda o estágio supervisionado e a sua oferta em articulação com projetos e programas de uma rede municipal de ensino (FRANCELINO DE SALES, 2011) e o outro trata sobre a constituição da identidade docente de professores pedagogos em início de carreira (AMORIM, 2016). É possível perceber que, mesmo com temáticas de estudo diferenciadas, todas as oito produções buscam a compreensão do processo formativo docente.

$\mathrm{Na}$ leitura dos resumos, foi possível identificarmos o direcionamento do problema e os objetivos das pesquisas. Os oito trabalhos tomam como problema de pesquisa a formação de professores, seja em âmbito inicial ou continuada. Os dois trabalhos que tratam da formação continuada focalizam a investigação sobre as concepções dos professores sobre sua própria formação, abordando a (re) construção teórica, a ressignificação da prática e as relações que os mesmos estabelecem entre formação continuada e inicial (RIBEIRO, 2006; SARTORI, 2009).

Nos quatro trabalhos que abordam o currículo do curso de Pedagogia, identificamos que dois investigaram a formação inicial na perspectiva da Educação Inclusiva (MACEDO, 


\section{Q DEVIR EDUCAÇÃO \\ ISSN: 2526-849X}

2010; OLIVEIRA, 2016), um avaliou a perspectiva dos docentes, discentes e egressos sobre a qualidade do ensino-aprendizagem das disciplinas da área de Estrutura e Funcionamento do Ensino (MENDES, 2011) e o outro investigou as ações dos atores do curso de Pedagogia em relação aos projetos de integração curricular (MELLO, 2013).

As outras duas produções possuem direcionamentos de problemas bem diferentes, uma investiga a situação profissional de professores iniciantes no que concerne a relação entre a formação inicial desses professores e o processo de constituição de suas identidades como docentes (AMORIM, 2016) e o outro desenvolve um estudo sobre o modo como o estágio supervisionado é oferecido para os estudantes do curso de Pedagogia no contexto de programas e projetos de uma rede municipal de ensino (FRANCELINO DE SALES, 2011).

Quanto aos sujeitos destes estudos, percebemos que os trabalhos apresentam significativas convergências, pois identificamos que três deles tiveram como sujeitos de pesquisa professores no exercício da docência em salas de aula da Educação Básica (AMORIM, 2016; RIBEIRO, 2006; SARTORI, 2009), especificamente nos anos iniciais do Ensino Fundamental, sendo que, dentre esses três trabalhos, apenas o que teve como foco os professores iniciantes, também contemplou como sujeito de pesquisa os professores da Educação Infantil (AMORIM, 2016).

Dos oito trabalhos localizados, quatro tiveram como sujeito de pesquisa membros da comunidade acadêmica. Dois focalizaram os docentes e discentes dos cursos de Pedagogia, mas também investigaram egressos, coordenadores pedagógicos e diretores do Centro de Educação dos referidos cursos (MELLO, 2013; MENDES, 2011). Nos outros dois trabalhos, um tomou os alunos/estagiários da disciplina Estágio Supervisionado como sujeitos (FRANCELINO DE SALES, 2011), e no outro, os sujeitos foram os alunos de uma disciplina intitulada Estudos sobre Necessidades Educacionais Especiais, que abordou uma metodologia diferenciada de trabalho (OLIVEIRA, 2016).

Apenas um dos trabalhos não teve sujeito de pesquisa, pois buscou compreender de que maneira a Educação Especial, na perspectiva da Educação Inclusiva, tem sido contemplada nos cursos de Pedagogia das três Universidades Públicas Estaduais de São Paulo, configurando-se numa pesquisa documental (MACEDO, 2010).

Sobre o caminho metodológico destas pesquisas, localizamos nos resumos alguns indícios que sinalizam a abordagem e também as técnicas de coleta de dados utilizadas. No resumo de seis trabalhos, encontramos os termos "pesquisa qualitativa", "natureza 


\section{Q DEVIR EDUCAÇÃO \\ ISSN: 2526-849X}

qualitativa" e "abordagem qualitativa" designando a abordagem de investigação (AMORIM, 2016; MACEDO, 2010; MELLO, 2013; RIBEIRO, 2006; OLIVEIRA, 2016; SARTORI, 2009). O trabalho que utilizou o termo "natureza qualitativa" se denominou de "estudo descritivo, de natureza qualitativa, constituindo-se num estudo de caso" (OLIVEIRA, 2016). Nos outros dois trabalhos, observamos que um utilizou o termo "quali quantitativa" e elegeu o Estudo de Caso como método de pesquisa (MENDES, 2011), e no outro não encontramos referência em relação a abordagem adotada (FRANCELINO DE SALES, 2011).

No que concerne às técnicas e procedimentos de coleta de dados, as pesquisas adotaram em comum os seguintes aspectos: duas aplicaram questionários (AMORIM, 2016; RIBEIRO, 2006); quatro utilizaram entrevistas (AMORIM, 2016; FRANCELINO DE SALES, 2011; MELLO, 2013; RIBEIRO, 2006; uma especificou a revisão bibliográfica como procedimento de pesquisa (FRANCELINO DE SALES, 2011) e três realizaram análise documental (FRANCELINO DE SALES, 2011; MACEDO, 2010; RIBEIRO, 2006), sendo que apenas duas especificaram que adotaram as técnicas de análise de conteúdo (FRANCELINO DE SALES, 2011; SARTORI, 2009).

Por fim, sobre os aportes teóricos que fundamentam as teses e dissertações localizadas, apenas cinco explicitam de maneira clara as bases de sustentação teórica que apoiaram a pesquisa (FRANCELINO DE SALES, 2011; MACEDO, 2010; MENDES, 2011; SARTORI, 2009; AMORIM, 2016). Três trabalhos abordam como referencial teórico os estudos, pesquisas, documentos oficiais e as legislações sobre políticas públicas educacionais, políticas de inclusão escolar, políticas de formação de professores, formação inicial oferecida nos cursos de Pedagogia, como também abordam como categoria temática a história, a avaliação e a gestão educacional (FRANCELINO DE SALES, 2011; MACEDO, 2010; MENDES, 2011). Apenas o trabalho de Sartori (2009) faz referência à categoria temática "práxis pedagógica/articulação teoria e prática" ao mencionar o uso dos princípios freireanos de ação-reflexão-ação como fundamentação teórica.

Dentre esses cinco trabalhos, identificamos que a única produção que destacou especificamente os autores utilizados na discussão teórica da investigação foi a dissertação de Amorim (2016), a qual apoiou-se em autores como Dubar, Marcelo Garcia, Hubberman e Gatti. Em relação aos demais trabalhos não encontramos, no corpo do texto dos resumos, os autores utilizados ou indícios que revelassem a perspectiva teórica que embasa a investigação realizada (MELLO, 2013; OLIVEIRA, 2016; RIBEIRO, 2006). 


\section{Q DEVIR EDUCAÇÃO \\ ISSN: 2526-849X}

As análises dos resumos, de maneira geral, evidenciam a preocupação dos autores com a formação de professores, com vistas a uma melhor compreensão do processo de formação inicial e/ou continuada perpassada. Embora a maioria das produções não focalize a articulação teoria e prática como categoria central, as investigações sobre o desenvolvimento da formação docente apontam para uma discussão sobre a presença ou ausência do referido binômio neste processo formativo.

\section{Considerações finais}

Na busca de analisar e apresentar a abordagem dispensada à temática articulação entre teoria e prática na produção acadêmica nacional vinculada aos programas de pós-graduação em Educação, especificamente nas teses e dissertações, pudemos perceber, a partir da leitura dos títulos, resumos e palavras-chave das produções, que a referida temática não se constitui como foco central nos trabalhos mapeados.

Os oito estudos localizados e apresentados neste escrito compreendem o período de 2006 a 2016, apontando para um arrefecimento no interesse pela temática nos últimos anos. Estes estudos, embora possuam temáticas específicas diferenciadas, evidenciam a preocupação sobre o processo formativo do professor, no entanto, discussões sobre a importância da articulação entre teoria e prática durante este processo formativo se faz presente apenas como resultados alcançados nestas produções. Identificamos também que apenas o trabalho de Sartori (2009), aponta a articulação teoria e prática dentre as categorias centrais de estudo.

Com base nessa constatação, de maneira geral, foi possível a identificação de que o tema referente a articulação entre teoria e prática na formação de professores pedagogos se faz presente nas teses e dissertações de maneira pulverizada, sem evidenciar, nos estudos recentes em âmbito nacional, uma preocupação contínua e central sobre o assunto na produção oriunda dos programas de pós-graduação stricto sensu em Educação.

Ratificamos a necessidade de debates centrais e atuais sobre a articulação teoria e prática, apontando para a indispensável presença dessa durante todo o processo de formação do professor pedagogo. Salientamos, assim, a necessidade de aprofundamento das discussões sobre a articulação teoria e prática na formação dos professores como temática central de estudos acadêmicos de teses e dissertações.

Revista Devir Educação, Lavras, vol.3, n.2, p.5-26 jul./dez., 2019. 


\section{Referências}

AMORIM, Aline Diniz de. O processo de constituição da identidade docente do professor iniciante: egressos do curso de Pedagogia da UNESP/Bauru. 2016. 150 f. Dissertação (Mestrado em Educação Escolar) — Universidade Estadual Paulista "Júlio de Mesquita Filho", Faculdade de Ciências e Letras, Campus Araraquara, São Paulo, 2016.

ANDRÉ, Marli Eliza Dalmazo Afonso de,et al. O papel do professor formador e das práticas de licenciatura sob o olhar avaliativo dos futuros professores. Revista Portuguesa de Investigação Educacional, vol. 12, 2012, p. 101-123.

BARDIN, L. Análise de conteúdo. 3. ed. Lisboa: Edições 70, 2004.

CANDAU, Vera Maria. Educação em Direitos Humanos. Revista Novamerica, Rio de Janeiro, n. 78, p. 36-39, 1998.

CANDAU, Vera Maria; LELIS, Isabel Alice.A Relação Teoria-Prática na Formação do educador. In: CANDAU, Vera Maria (Org.). Rumo a uma Nova Didática. 10 ed. Petrópolis: Vozes. 1999. p.56-72.

CHIARELO, Sheila Mara de Melo Rodrigues. O diálogo entre teoria e prática no cenário das políticas públicas de formação inicial de professores à docência de pedagogia: os casos USP, UNESP E UNICAMP. 2017. 146 f. Dissertação (Mestrado Profissional - Políticas Públicas), Universidade Estadual Paulista, Faculdade de Ciências Humanas e Sociais, Franca, 2017.

CRUZ, Giseli Barreto da. Teoria e prática no curso de pedagogia. Educação e Pesquisa, São Paulo, v. 38, n. 1, p.149-164, 2012.

FARIAS, Isabel Maria Sabino. Inovação, mudança e cultura docente. Brasília: Liber Livro, 2006.

FORMOSINHO, João (Coord.). Formação de professores: aprendizagem profissional e acção docente. Portugal: Porto Editora, 2009.

FRANCELINO DE SALES, Claudemir. O estágio e a política de formação do educador: um estudo a partir de programas e projetos da rede municipal de ensino do Recife. 2011. 111f. Dissertação (Mestrado em Educação) - Universidade Federal de Pernambuco, Recife, 2011.

FRANCO, Maria Amélia do Rosário Santoro. Pedagogia e prática docente. 1. ed. São Paulo: Cortez, 2012.

FULLAN, Michael. The new meaning of educational change. New York: Teachers College, 1991.

GARCIA, Walter Esteves. Educação: visão teórica e prática pedagógica. São Paulo: McGraw-Hill, 1977. 
GARCIA, Carlos Marcelo. El primer ano de enseñanza: análisis del processo del socialización de profesores iniciantes. Revista do Educación, núm. 300, 1993, págs. 225-277.

GARCIA, Carlos Marcelo. Formação de professores: para uma mudança educativa. Porto: Porto Editora, 1999.

GATTI, Bernadete Angelina. Formação de professores no Brasil: características e problemas. Educ. Soc. Campinas, v. 31, n. 113, p. 1355-1379, out./dez. 2010.

GATTI, Bernadete Angelina. A formação inicial de professores para a Educação Básica: as licenciaturas. Revista USP. São Paulo, n. 100, p. 33-46, dez./jan./fev. 2014.

GHEDIN, Evandro, OLIVEIRA, Elisangela S. de; ALMEIDA, Whasgthon A. de Almeida. Estágio com pesquisa. São Paulo: Cortez, 2015.

GIOVANNI, Luciana Maria; GUARNIERI, Maria Regina. Pesquisas sobre professores iniciantes e as tendências atuais de reforma da formação de professores: distância, ambiguidades e tensões. In: GIOVANNI, Luciana Maria; MARIN, Alda Junqueira (Org.). Professores iniciantes: diferentes necessidades em diferentes contextos. Araraquara, SP: Junqueira\&Marin, 2014.

IMBERNÓN, Francisco. Formação docente e profissional: formar-se para a mudança e a incerteza. São Paulo: Cortez, 2011.

LIMA, Maria Socorro Lucena. A hora da prática: reflexões sobre o estágio supervisionado e ação docente. 2. ed. Fortaleza: Edições Demócrito Rocha, 2004.

MACEDO, Natalia Neves. Formação de professores para a educação inclusiva nos cursos de Pedagogia das Universidades Públicas Paulistas. 2010. 140f. Dissertação (Mestrado em Educação Especial) - Universidade Federal de São Carlos, São Paulo, 2010.

MARCELO GARCÍA, Carlos; VAILLANT, Denise. Ensinando a ensinar: As quatro etapas de uma aprendizagem. Curitiba: Ed. UTFPR, 2012.

MENDES, Débora Lúcia Lima Leite. Estrutura e funcionamento de ensino e a gestão educacional: avaliação de disciplinas em cursos de pedagogia e licenciatura na Universidade Federal do Ceará. 2011. 206f. - Tese (Doutorado em Educação) - Universidade Federal do Ceará, Fortaleza, 2011.

MELLO, Marilice Pereira Ruiz do Amaral. Formação inicial de professores e projetos integradores do curso de Pedagogia: desafios e possibilidades. 2013. 224f. Tese (Doutorado em Educação) - Pontifícia Universidade Católica de São Paulo, São Paulo, 2013.

NONO, Maévi Anabel. Professores iniciantes: o papel da escola em sua formação. Porto Alegre: Editora Mediação, 2011.

NÓVOA, Antônio (Coord.). Os professores e a sua formação. 2 ed. Lisboa: Dom Quixote, 1995.

NÓVOA, António (Org.). Vidas de professores. 2a ed. Porto: Porto Editora, 2000. 


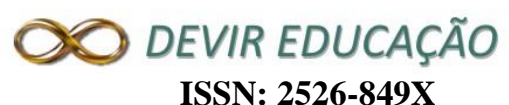

ISSN: 2526-849X

NÓVOA, António. Professores: imagens do futuro presente. Lisboa: Educa, 2009.

RIBEIRO, Jacira Chaves. Formação continuada e trabalho pedagógico: o caso de uma professora egressa do curso de Pedagogia para professores em exercício no início de escolarização-PIE. 2006. 137f. Dissertação (Mestrado em Educação) - Universidade de Brasília, 2006.

OLIVEIRA, Adriana. Inclusão Escolar e Formação Inicial de Professores: A Metodologia da Problematização Como Possibilidade da Construção dos Saberes Inclusivos. 2016145 f. Tese (Doutorado em Educação Escolar) - Universidade Estadual Paulista "Júlio de Mesquista Filho", Araraquara, 2016.

PIMENTA, Selma Garrido. O estágio na formação de professores: unidade entre teoria e prática? Cad. Pesq., São Paulo, n. 94, 1995.

PIMENTA, Selma Garrido. Formação de professores - saberes da docência e identidade do professor. Nuances, v. 3, n. 1, p. 5-12, set. 1997.

PIMENTA, Selma Garrido. A Didática como mediação na construção da identidade do professor uma experiência de ensino e pesquisa na Licenciatura. ln: OLIVEIRA, Maria Rita Neto Sales; ANDRÉ, Marli (Orgs.). Alternativas ao ensino de didática. Campinas: Papirus, 1997.

PIMENTA, Selma Garrido. Formação de professores: identidade e saberes da docência. In: PIMENTA, Selma Garrido. (Org). Saberes pedagógicos e atividade docente. São Paulo: Cortez Editora, 1999.

PIMENTA, Selma Garrido; LIMA Maria Socorro Lucena. Estágio e Docência. São Paulo: Cortez, 2004.

PIMENTA, Selma Garrido; LIMA, Maria Socorro Lucena. Estágio e docência: diferentes concepções. Revista Poíesis, v. 3, n. 3 e 4, p. 5-24, 2005/2006.

SARTORI, Jerônimo. Formação do professor em serviço: da (re)construção teórica e da ressignificação da prática. 2009. 209f. Tese (Doutorado em Educação) - Universidade Federal do Rio Grande do Sul, Porto Alegre, 2009.

SAVIANI, Demerval. Pedagogia: o espaço da educação na universidade. Cadernos de Pesquisa, v. 37, nº 130, p. 99-134, jan. 2007.

TEIXEIRA, Marina Codo Andrade. O compromisso formativo dos cursos de Administração com a realidade local. 2015. 175f. Tese (Doutorado em Currículo) Pontifícia Universidade Católica de São Paulo, São Paulo, 2015.

VAILLANT, Denise; MARCELO, Carlos. Ensinando a Ensinar: as quatro etapas de uma aprendizagem. Curitiba: Ed. UTFPR, 2012.

VÁZQUEZ, Adolfo Sanchez. Filosofia da Práxis. Tradução de Luiz Fernando Cardoso. Rio de Janeiro: Paz e Terra, 1977. 
ISSN: 2526-849X

VIANA, Herika Paes Rodrigues. A formação de professores de História: articulação teoria e prática. 2017. 133f. Dissertação (Mestrado em História) - Universidade Federal Rural de Pernambuco, Recife, 2017. 